\title{
Challenging Permanent-Pacemaker Implantation in a Patient with Postpneumonectomy-like Syndrome as a Late Sequela of Treated Pulmonary Tuberculosis
}

\author{
Roberto Cerrud-Rodriguez ${ }^{1 *}$, Mohammed Algodii ${ }^{1}$, Umair Chishti ${ }^{1}$ and Salim Baghdadi ${ }^{2}$ \\ ${ }^{1}$ Department of Internal Medicine, SBH Health System, USA \\ ${ }^{2}$ Department of Clinical Electrophysiology, SBH Health System, USA
}

Submission: March 27, 2018; Published: May 01, 2018

*Corresponding author: Roberto Cerrud-Rodriguez, MD, Department of Internal Medicine, SBH Health System, 4422 3rd Avenue, Bronx, NY, 10457, USA, Tel: 718-960-9000; Email: robertocerrud@gmail.com

\begin{abstract}
A 55-year-old male, from the Dominican Republic, with a history of treated pulmonary tuberculosis of the right lung, presents to the primary care clinic with a history of several months of palpitations, unrelated to physical activity. Chest imaging showed right lung peripheral pleural thickening and parenchymal volume loss with mediastinal shift to the right. Subsequent Pulmonary Function Tests: showed severe airway obstruction, without response to bronchodilators and severely decreased total lung capacity and diffusing capacity. EKG: sinus rhythm. The patient was then diagnosed with the Post-pneumonectomy-like syndrome.

Due to persistent palpitations, the patient was referred to the Cardiology clinic. ECHO was normal. Holter monitor with sinus pauses of up to 10.6 seconds. After this abnormal finding, he was diagnosed with sick sinus syndrome and referred to the Electrophysiology service (EP), who decided that a permanent pacemaker (PPM) had to be implanted, due to the severity and persistence of the patient's symptoms. Following this procedure, the PPM was implanted correctly and the patient had no recurrence of his symptoms.

The post-pneumonectomy-like syndrome occurs when an insult (infectious or otherwise) destroys lung parenchymal tissue, followed by a compensatory overexpansion of the contralateral lung, with subsequent mediastinal shifting. There have been few reported cases of this syndrome as a long-term sequela of pulmonary tuberculosis. In symptomatic patients, the treatment options are mainly surgical, with repositioning of the mediastinum and insertion of tissue expanders. In patients with no related symptoms, as was the case with our patient, a conservative approach with routine follow up is recommended.
\end{abstract}

Keywords: Sick sinus syndrome; Permanent pacemaker; Pulmonary tuberculosis; Postpneumonectomy-like syndrome; Pneumonectomy-like syndrome

\section{Introduction}

We present for your consideration the case of a 55-yearold male with a history of treated pulmonary tuberculosis that subsequently developed a post-pneumonectomy-like syndrome of his right lung, with mediastinal shift. Later on, he developed sick sinus syndrome requiring the implantation of a permanent pacemaker. Given the rarity of the post-pneumonectomylike syndrome and the technical difficulties presented by the pacemaker placement, we thought that sharing our technique will assist our colleagues who face similar technical dilemmas.

\section{Case Report}

A 55-year-old male, from the Dominican Republic, presented to the electrophysiology clinic after being referred by his primary care physician, with an abnormal ambulatory Holter monitor showing sinus pauses of up to 10.6 seconds.

The patient had originally been seen in the primary care clinic with a history of several months of palpitations, unrelated to physical activity. The patient also endorsed shortness of breath and palpitations during sleep, which caused him to wake up during the night, in order "to catch his breath". No symptoms were reported during daytime and he was able to walk $>4$ blocks at a time without feeling short of breath nor developing chest pain.

A CT scan of the thorax showed findings consistent with the post-pneumonectomy-like syndrome (Figure $1 \& 2$ ). Subsequent Pulmonary Function Tests: showed severe airway obstruction, 


\section{Journal of Cardiology \& Cardiovascular Therapy}

without response to bronchodilators and severely decreased total lung capacity and diffusing capacity, EKG: sinus rhythm.

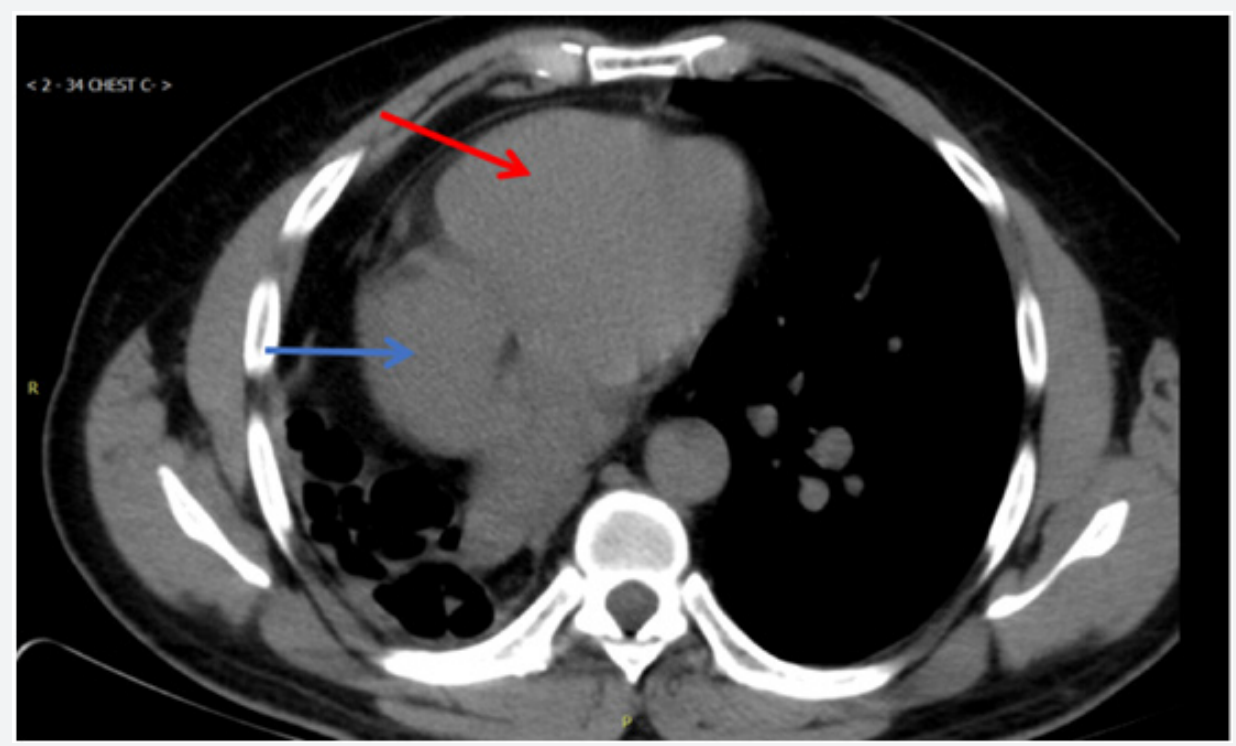

Figure 1: Blue arrow to RA, right arrow to RV.

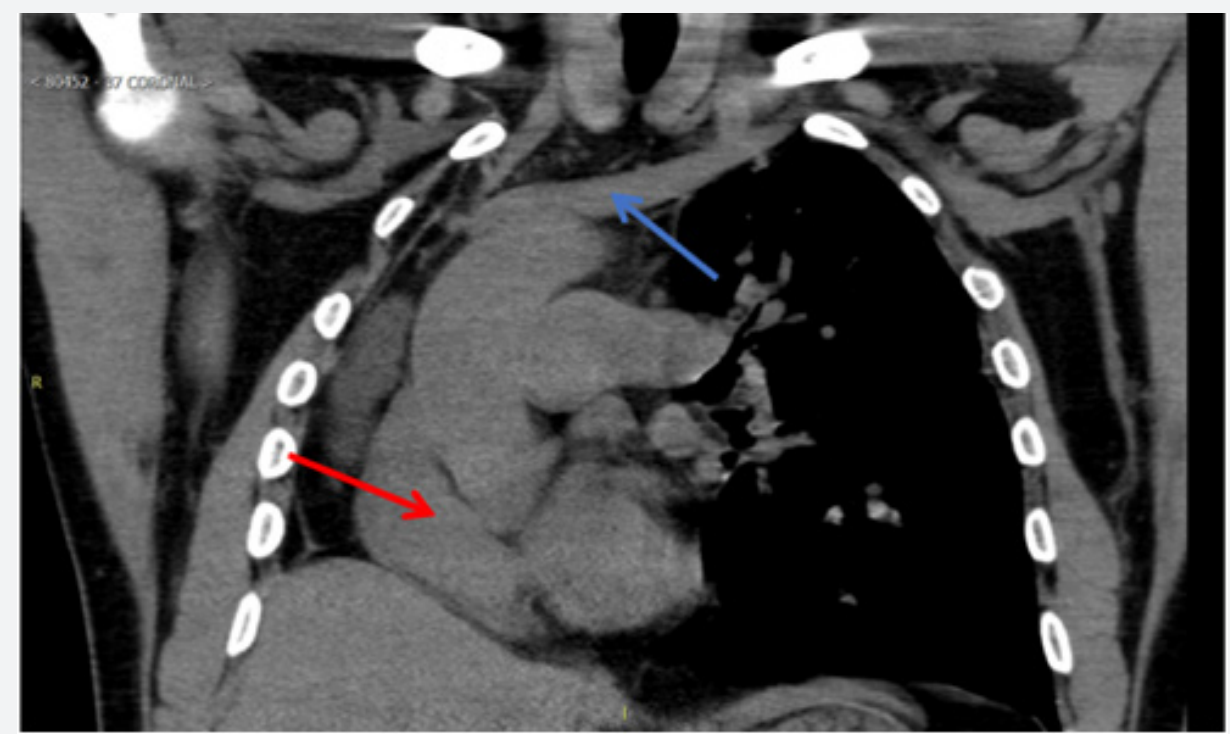

Figure 2: Blue arrow to left subclavian vein, red arrow to right atrium.

His past medical history was significant for treated pulmonary tuberculosis of the right lung (1993), hypertension, diabetes. The patient is a life-long non-smoker, but had a history of chronic exposure to burning biomass used as fuel for cooking while in the Dominican Republic.

On pertinent physical examination, the lungs had equal breath sounds bilaterally, no rales/wheezing. Cardiac examination revealed a point of maximal impulse displaced anteriorly, with a regular rate and rhythm on auscultation, no murmurs.

It was decided in the electrophysiology clinic that the best course of action for the patient's sick sinus syndrome was to place a permanent pacemaker (PPM). A transthoracic echocardiogram was obtained, with a normal left ventricular wall thickness and normal ejection fraction.

The patient was taken to the cardiac cath lab for implantation of a permanent pacemaker. Right ventricular (RV) lead placement was as follows: venous access was through cephalic vein dissection. Fluoroscopy images showed that the patient's heart was displaced to the right, which made it impossible to advance the RV lead into the right ventricle despite multiple attempts with different manually curved stylets. 9Fr coronary sinus (CS) delivery system (Biotronik -Selectra Extended Hook 45cm, model number 375527 ) was used to get into the RV over Terumo glide 
wire. The ventricular lead was next introduced through the 9Fr long CS sheath and positioned into the right ventricular lower septum. Following this procedure, the permanent pacemaker was successfully placed (Figure 3).

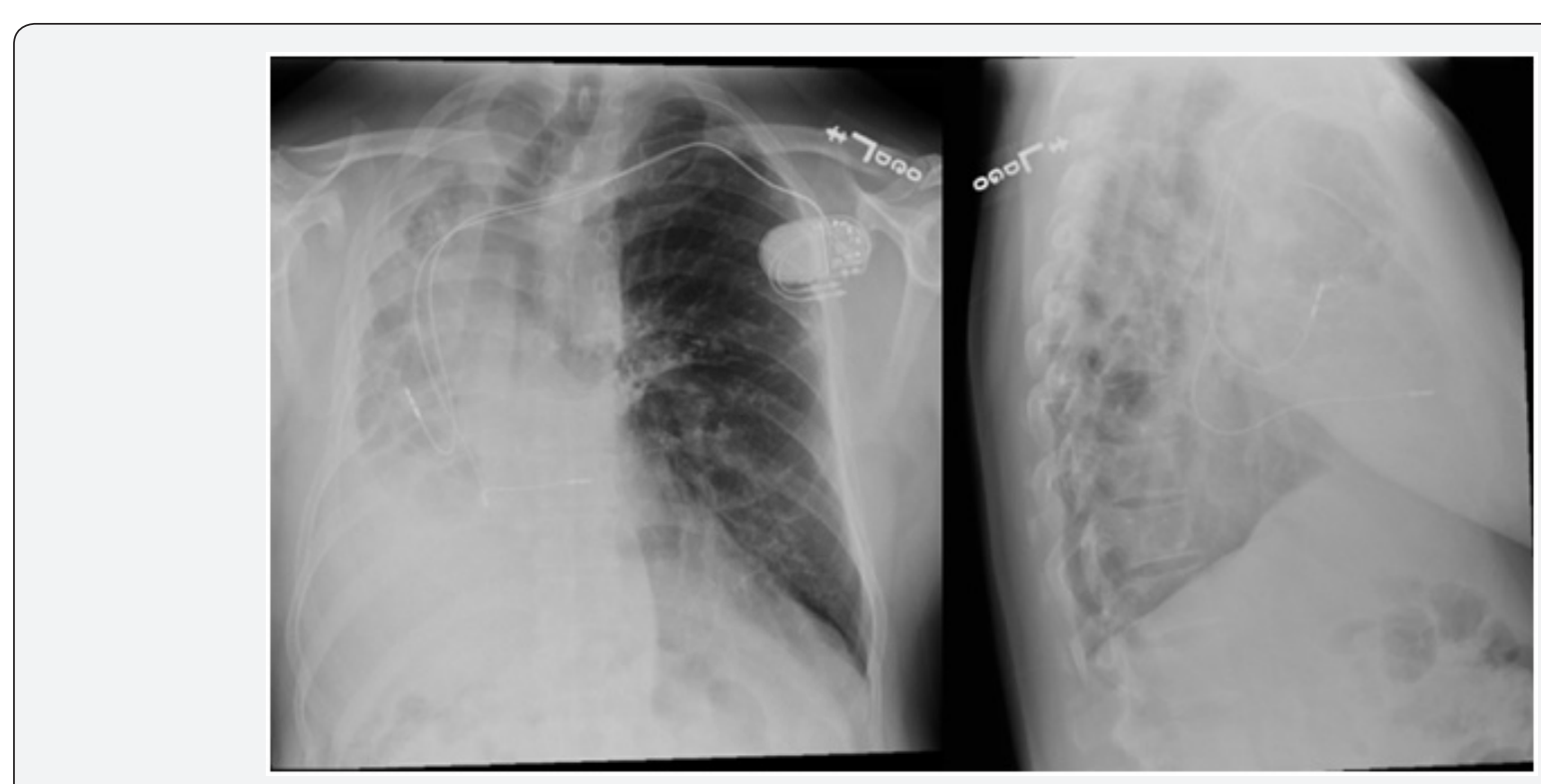

Figure 3: Chest radiograph showing right lung peripheral pleural thickening and parenchymal volume loss with mediastinal shift. Dual lead pacemaker with leads overlying RA and RV.

\section{Discussion}

The postpneumonectomy-like syndrome occurs when an insult (infectious or otherwise) destroys lung parenchymal tissue (called autopneumonectomy), followed by a compensatory overexpansion of the contralateral lung, which results in mediastinal shifting [1,2].

This syndrome tends to present clinically as progressively worsening dyspnea. Few cases of this syndrome have been described as a late sequela of pulmonary tuberculosis. One case was reported of the postpneumonectomy-like syndrome in a patient as a late complication of chemoradiation therapy for recurrent Hodgkin's lymphoma, due to extreme fibrosis and collapse of the affected lung [3].

In symptomatic patients, the treatment options for this entity are mainly surgical, with repositioning of the mediastinum and insertion of one or more tissue expanders [1]. In patients' such as ours, with none-to-minimal symptoms, a conservative approach can be followed, with regular follow-up.

In our patient with the postpneumonectomy-like syndrome, access through the cephalic vein and the superior vena cava to advance the RV lead was impossible due to mediastinal and heart shifting to the right. In cases with such distorted thoracic or vascular anatomy, several maneuvers to facilitate RV lead placement have been reported. Among them, manual reshaping of the stylet into a U-shaped stylet depends on thoracic anatomy (which necessitates considerable maneuvering) [4], ventricular lead placement in the left ventricular branch of the coronary sinus, and use of an atrial "J" stylet for ventricular lead placement.
In this case, after multiple failure attempts advancing the RV lead with different manually curved stylets, we report an alternative method using coronary sinus cannulation as method of delivery without reportable complications. This approach was based on utilizing a long sheath over gliding wire to reach the RV apex.

Using a gliding wire give us an advantage as it is easily manipulated and directed toward to right ventricle, which make advancing the sheath to RV much easier overcoming the difficult anatomy. This delivery method using Selectra extended hook was effective as it allowed rapid placement of the lead into RV septum reducing implantation time and radiation exposure. This method has successfully used before in reported cases dealing with abnormal vascular anatomy such as PLSVC [5].

A learning point from this case, we recommend that all patients with a known history of pulmonary tuberculosis, regardless of treatment status, who for any reason requiring pacemaker implantation, to be subjected to routine pre-procedure chest imaging studies, to determine if there is any distortion of the normal anatomy, this would help with better planning using the right method of access, and having the appropriate equipment such as long sheath to access the coronary sinus available on site. This would save time and avoid multiple attempts with manually curve stylet, which may result in undesirable complications.

To the best of our knowledge, there is no previous report of a patient with a pneumonectomy-like syndrome secondary to treated pulmonary tuberculosis that required a permanent pacemaker implantation for management of sick sinus syndrome. 


\section{References}

1. Lee Y, Kwan Kim H, Lee S, Kim H, Kim J (2008) Surgical correction of postpneumonectomy-like syndrome in a patient with a tuberculosisdestroyed lung. J Thorac Cardiovasc Surg 136(3): 780-781.

2. Kam J, Dieguez J, Doraiswamy V, Alberaqdar E, Ramchandran A, et al (2013) Postpneumonectomy-like syndrome presenting in a patient with treated pulmonary tuberculosis: a case report. J Med Case Rep 7: 40 .

3. Veronesi G, Spaggiari L, Solli P, Leo F, Villa G, et al. (2002) Postpneumonectomy-like syndrome after chemoradiation therapy for lymphoma. Ann Oncol 13(12): 1945-1947.
4. Biffi M, Boriani G, Frabetti L, Bronzetti G, Branzi A (2001) Left superior vena cava persistence in patients undergoing pacemaker or cardioverter-defibrillator implantation: a 10- year experience. Chest $120(1): 139-144$

5. Markewitz A, Mattke S (1996) Right ventricular implantable cardioverter defibrillator lead implantation through a persistent left superior vena cava. Pacing Clin Electrophysiol 19(9): 1395-1397.

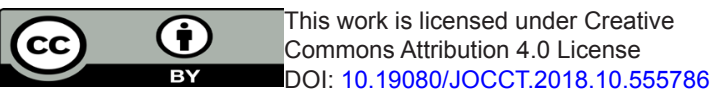

Your next submission with Juniper Publishers will reach you the below assets

- Quality Editorial service

- Swift Peer Review

- Reprints availability

- E-prints Service

- Manuscript Podcast for convenient understanding

- Global attainment for your research

- Manuscript accessibility in different formats

( Pdf, E-pub, Full Text, Audio)

- Unceasing customer service

Track the below URL for one-step submission https://juniperpublishers.com/online-submission.php 